\title{
Uganda at risk of reversing HIV/AIDS progress
}

Published at www.cmaj.ca on Sept. 24

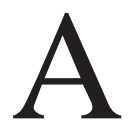
11 Rachel Alum could think about was dying. Nightmares disrupted her sleep in a church in northern Uganda, where the widowed mother of four was camped out with her children. She was weak, covered in skin rashes and dehydrated from vomiting and diarrhea. She was HIV-positive, and her immune system was almost destroyed, leaving her at risk for fatal infections.

"I used to cry all the time, especially when I saw my first- and last-born," she says. "I had no hope."

After her husband died, Alum says his family took her belongings and chased her from their house. She ended up at the church. But she was afraid of what would happen to her children if she died and left them alone. Already, instead of going to school, they washed clothes and carried water to earn enough to buy flour for a thin porridge, yams, pumpkins and cassava leaves.

Once the country with the world's highest HIV/AIDS infection rate, Uganda has been Africa's success story in the last 10 years. By 2002, the population's HIV rate had dropped to $6 \%$ from a high of $30 \%$ in urban areas in 1992, according to the Uganda Aids Commission.

Early openness about the cause of HIV/AIDS and leadership from Uganda's president and other national figures, public health campaigns against multiple partners, easy access to testing and, beginning in 2004, free antiretroviral drugs, contributed to beating back the disease that continues to ravage the rest of the continent.

But there are worrisome indicators that HIV/AIDS is again on the rise. Dr. David Kihumuro-Apuuli, head of the Uganda Aids Commission, recently told reporters that the $6 \%$ statistic is eight years old, that people continue to resist testing and that the number of new HIV/AIDS infections is growing.

Moreover, health care workers say

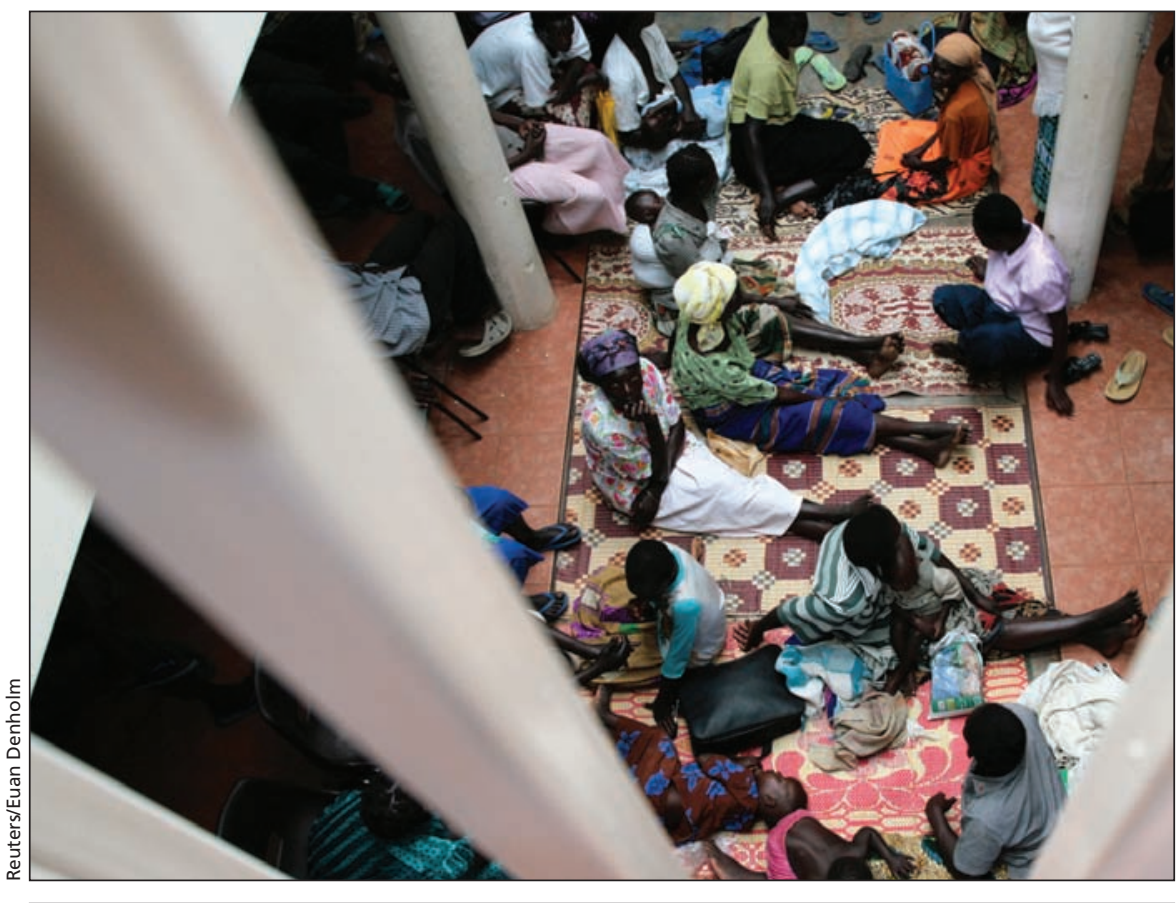

Patients with HIVIAIDS sit at a counselling facility in Gulu, Uganda.

the perception that AIDS is now a chronic rather than a terminal disease has led to less safe sexual practices, while the first generation of HIV-positive children is coming of age and becoming sexually active.

As well, the era of free antiretrovirals is ending and Uganda has introduced a quota for free drugs. In 2008, only $33 \%$ of those who needed the drugs got them, according to UNAIDS.

Women account for $57 \%$ of all adults living with HIV, according to statistics provided by the HIV/AIDS organization Avert. They are also economically vulnerable. When a couple marries, the husband pays a bride price. If he dies, his family is legally entitled to claim her property, as Alum discovered. Sometimes, they also take the children.

"That happens all the time. The law is actually on the men's side," says Marilyn Skinner, who in 2007 established Living Hope - Watoto Church. Living Hope operates programs in Kampala and Gulu that provide med- ication, support and vocational training to women diagnosed with HIV/AIDS. It also provides start-up capital for women to launch their own businesses. An offshoot of Watoto Church in Kampala, Living Hope also offers parenting classes.

Living Hope's major goal is to keep the women alive to parent their own children, so there will be fewer HIV/AIDS orphans, says Viola Lutara, who runs the program, along with Skinner. "The best place for any child is with its mother," Lutara adds.

The AIDS Support Organisation referred Alum to Living Hope. She was a tailor before she married and has since sharpened those skills. She is now among 2100 women selling handmade dresses, purses, tablecloths, placemats and jewellery to help support themselves. About 1200 are in Kampala and the remainder are in Gulu. Many of those women were abducted as children and forcibly "married" to soldiers in the Lord's Resistance Army. Often rejected by their families when they 
tried to return to their villages, some were even mutilated by the Lord's Resistance Army soldiers for trying to escape.

Today, the Living Hope women, including Alum, dream of a better future.

"I am happy, and my children are all happy," she says. "Now they are no longer fetching water for money. They are in school. We are eating daily, and paying school fees. I get that I'm smart. Through Living Hope, I have learned a lot of things."

With her CD4 count at 385 closer to the 500 number considered normal - Alum feels well. She hopes to establish a design and tailoring business and someday buy land. "Even if I die, they could not chase my children away from their home," she says. - Laura Eggertson, Kampala, Uganda

DOI:10.1503/cmaj.109-3672

Laura Eggertson, a long-time CMAJ correspondent, penned this story while in Uganda working as a volunteer for a Watoto Child Ministries building team. 